\title{
Increase of a Fibrinolytic Enzyme Production through Promoter Replacement of aprE3-5 from Bacillus subtilis $\mathrm{CH} 3-5$
}

\author{
Zhuang Yao', Yu Meng ${ }^{1}$, Huong Giang Le' ${ }^{1}$, Se Jin Lee', Hye Sung Jeon ${ }^{1}$, Ji Yeon Yoo ${ }^{1}$, and \\ Jeong Hwan Kim ${ }^{1,2 *}$ \\ 'Division of Applied Life Science (BK21 Four), Graduate School, Gyeongsang National University, Jinju 52828, \\ Republic of Korea \\ ${ }^{2}$ Institute of Agriculture and Life Science, Gyeongsang National University, Jinju 52828, Republic of Korea
}

Bacillus subtilis CH3-5 isolated from cheonggukjang secretes a 28 kDa protease with a strong fibrinolytic activity. Its gene, aprE3-5, was cloned and expressed in a heterologous host (Jeong et al., 2007). In this study, the promoter of aprE3-5 was replaced with other stronger promoters $\left(P_{\text {cry3AA }} P_{10}\right.$, $\left.\mathbf{P}_{\mathrm{SG} 1}, \mathbf{P}_{\text {srfA }}\right)$ of Bacillus spp. using PCR. The constructed chimeric genes were cloned into pHY300PLK vector, and then introduced into $B$. subtilis WB600. The $P 10$ promoter conferred the highest fibrinolytic activity, i.e., 1.7-fold higher than that conferred by the original promoter. Overproduction of the $\mathbf{2 8}$ kDa protease was confirmed using SDS-PAGE and fibrin zymography. RTqPCR analysis showed that aprE3-5 expression was 2.0-fold higher with the P10 promoter than with the original promoter. Change of the initiation codon from GTG to ATG further increased the fibrinolytic activity. The highest aprE3-5 expression was observed when two copies of the $P_{10}$ promoter were placed in tandem upstream of the ATG initiation codon. The construct with P10 promoter and ATG and the construct with two copies of P10 promoter in tandem and ATG exhibited $117 \%$ and $148 \%$ higher fibrinolytic activity, respectively, than that exhibited by the construct containing P10 promoter and GTG. These results confirmed that significant overproduction of a fibrinolytic enzyme can be achieved by suitable promoter modification, and this approach may have applications in the industrial production of AprE3-5 and related fibrinolytic enzymes.

Keywords: Bacillus subtilis, promoter replacement, gene expression, fibrinolytic enzymes

Received: March 15, 2021 Accepted: May 6, 2021

First published online: May 7, 2021

*Corresponding author Phone: +82- 55-772-1904 Fax: +82-55-772-1909 E-mail : jeonghkm@gnu.ac.kr

pISSN 1017-7825 elSSN 1738-8872

Copyright(C) 2021 by The Korean Society for Microbiology and Biotechnology

\section{Introduction}

Fibrinolytic enzymes secreted by some Bacillus spp. have been the subject of many researches owing to their application as potential anti-thrombotic agents $[1,2]$. Nattokinase is the most well-known enzyme, and commercially sold as a neutraceutical supplement. The overproduction of fibrinolytic enzymes, such as nattokinase, is important for the development of various products that contain them. To achieve this goal, various methods have been tried including screening of novel strains with strong fibrinolytic activities [3-5], optimizing the cultural conditions [6,7], construction of host strains where fibrinolytic genes were integrated into the chromosome $[8,9]$, and improvements of fibrinolytic genes through in vitro mutagenesis $[10,11]$. One of the most efficient methods for increasing gene expression is the replacement of the original promoter with a known stronger promoter because an increase in the transcription frequency results in an increase in the production of gene products [12].

Previously, we cloned a gene (aprE3-5) encoding the major fibrinolytic enzyme of B. subtilis $\mathrm{CH} 3-5$, which was isolated from cheonggukjang, Korean fermented soybean food. aprE3-5 encodes a preproenzyme that yields a mature $28 \mathrm{kDa}$ enzyme. aprE3-5 was expressed in a heterologous host, B. subtilis WB600 [13]. In this study, we constructed chimeric aprE3-5 genes, wherein the original promoter was replaced with one of the four known strong Bacillus spp. promoters. Furthermore, we constructed $a p r E$ genes wherein the initiation codon was changed from GTG to ATG and two copies of the most efficient promoter, i.e., P10, were placed in tandem upstream of the ATG initiation codon. We found that promoter replacement along with other modifications were effective in achieving the overproduction of AprE3-5 and in increasing the fibrinolytic activity of the host cell.

\section{Materials and Methods}

Construction of aprE3-5 Genes with Its Promoter Replaced with Other Promoter

Primers were designed to amplify aprE3-5 with its -35 and -10 promoter sequences were replaced with those from other Bacillus promoters (Table 1). PCR reactions were performed using a MJ mini personal thermal cycler 
Table 1. Primers used in this study.

\begin{tabular}{llcc}
\hline \multicolumn{1}{c}{ Primers } & \multicolumn{1}{c}{ Restriction site } & -35 & \multicolumn{2}{c}{ Sequences } & References \\
\hline aprE3-5-F & 5'-CGCGGATCCGGGTCTACTAAAATATTATTCCATCTATTACAATAAATTC -3' & 13 \\
Pcry3A-F & 5'-CGCGGATCCGGGTTGCAAAAAATATTATTCCATCTATTAAGCTAAATTC -3' & 14 \\
P10-F & 5'-CGCGGATCCGGGTTGACAAAAATATTATTCCATCTATTAAACTAAATTC -3' & 15 \\
PSG1-F & 5'-CGCGGATCCGGGTTGACAAAAATATTATTCCATCTATTACAATAAATTC -3' & 16 \\
PsrfA-F & 5'-CGCGGATCCGGGGTGATAAAAATATTATTCCATCTATTAAACTAAATTC -3' & 17 \\
aprE3-5-R & 5'-GCGAATTCGAGAACAGAGAAGCCGCT -3' & 13 \\
\hline
\end{tabular}

The restriction site was underlined: BamHI (forward primer) and EcoRI (reverse primer).The -35 and -10 promoter regions were in bold and underlined.

(Bio-Rad, USA). pHY3-5 (pHY300PLK containing aprE3-5) was used as the template DNA [13]. The reaction mixture $(50 \mu \mathrm{l})$ consisted of $1 \mu \mathrm{l}$ of template DNA, $1 \mu \mathrm{l}$ of each primer $(10 \mu \mathrm{M}), 5 \mu \mathrm{l}$ of dNTPs $(0.25 \mathrm{mM})$, and $0.5 \mu \mathrm{l}$ of ExTaq DNA polymerase (Takara, Japan). Amplification conditions were as follows: $94^{\circ} \mathrm{C}$ for $5 \mathrm{~min}, 30 \mathrm{cycles}$ of $94^{\circ} \mathrm{C}$ for $30 \mathrm{~s}, 64^{\circ} \mathrm{C}$ for $30 \mathrm{~s}, 72^{\circ} \mathrm{C}$ for $40 \mathrm{~s}$, and a final extension at $72^{\circ} \mathrm{C}$ for $5 \mathrm{~min}$.

\section{Introduction of Chimeric aprE3-5 Genes into B. subtilis WB600}

Amplified DNA was digested with BamHI and EcoRI, and ligated with pHY300PLK $\left(4.87 \mathrm{~kb}, \mathrm{Ap}^{\mathrm{R}}, \mathrm{Tc}^{\mathrm{R}}\right)$, an E. coli-Bacillus shuttle vector. The ligation mixture was used to transform B. subtilis WB600 competent cells [18]. Preparation of B. subtilis WB600 competent cells and electroporation $(200 \Omega, 21 \mathrm{kV} / \mathrm{cm})$ were done as reported previously [13]. Transformants (TFs) on LB agar plates with tetracycline $(15 \mu \mathrm{g} / \mathrm{ml})$ were screened for the recombinant plasmids. Plasmid DNA was prepared by using commercial kit (iNtRON Biotechnology, Korea), and DNA sequencing was done. Restriction enzyme digestion and agarose gel electrophoresis were performed according to the standard methods [19].

\section{Growth and Fibrinolytic Activities of $B$. subtilis TFs}

B. subtilis TFs were cultivated in LB broth with tetracycline $(15 \mu \mathrm{g} / \mathrm{ml})$ at $37^{\circ} \mathrm{C}$ with shaking. Aliquots were taken at $12 \mathrm{~h}$ intervals, and the $\mathrm{OD}_{600}$ values were measured. Culture was centrifuged at $4,000 \times g$ for $10 \mathrm{~min}$ at $4^{\circ} \mathrm{C}$ and the supernatant was used as a crude sample for fibrinolytic activity measurement. Fibrinolytic activity was measured by the fibrin plate method as described previously [20].

\section{SDS-PAGE and Fibrin Zymography}

Supernatants obtained as above were analyzed by SDS-PAGE and fibrin zymography. For SDS-PAGE, proteins $(10 \mu \mathrm{g})$ in the supernatant was concentrated by TCA precipitation, and loaded onto a $10 \%$ acrylamide gel after boiled for $10 \mathrm{~min}$ in $4 \mathrm{X}$ SDS sample buffer. For fibrin zymography, supernatant $(1 \mu \mathrm{g})$ was loaded without TCA concentration. Fibrin gel preparation and fibrin zymography were done as described previously [20]. The Dokdomarker (EBM-1034, Elpis-Biotech., Korea) was used as the size marker.

\section{Reverse Transcription (RT)-qPCR Analysis}

RNA was prepared from $48 \mathrm{~h}$ culture of $B$. subtilis WB600 TF by using Trizol/bead method [21], and treated with RQ1 RNase-free DNase (Promega, USA). RT-PCR was done using one-step RT-PCR premix kit (iNtRON Biotechnology, Korea). aprE3-5 was amplified by using primer pair in Table 2 . The $20 \mu$ l reaction mixture consisted of $8 \mu \mathrm{l}$ of premix, each $1 \mu \mathrm{l}$ of forward and reverse primer, $1 \mu \mathrm{l}$ of RNA (200 ng), and $9 \mu \mathrm{l}$ of DEPC-treated water. The reaction was started by $30 \mathrm{~min}$ incubation at $45^{\circ} \mathrm{C}$, followed by initial denaturation at $94^{\circ} \mathrm{C}$ for $5 \mathrm{~min}$. PCR cycles consisted of denaturation at $94^{\circ} \mathrm{C}$ for $1 \mathrm{~min}$, annealing at $53^{\circ} \mathrm{C}$ for $1 \mathrm{~min}$, and extension at $72^{\circ} \mathrm{C}$ for $1 \mathrm{~min}$. A total of $25 \mathrm{cycles}$ were repeated, and the final extension was done at $72^{\circ} \mathrm{C}$ for $5 \mathrm{~min} .16 \mathrm{~S}$ rRNA gene was used as a control, and primer pair $27 \mathrm{~F}$ and $1492 \mathrm{R}$ were used for the amplification. PCR results were checked by agarose gel electrophoresis using a $1 \%$ gel and iVDye $1 \mathrm{~kb}$ DNA Ladder (GenDepot, USA) as a size marker.

Quantitative real-time PCR was done using the reverse transcription PCR products as the templates. qPCR reactions were performed by using primer pairs in Table 2 , and the reaction mixture consisted of $10 \mu \mathrm{l}$ of SYBR-

Table 2. Primers used for reverse transcription PCR.

\begin{tabular}{|c|c|c|c|c|}
\hline PCR reaction & Genes name & Primer pairs & Sequences & Expected size \\
\hline \multirow[t]{4}{*}{ RT-PCR } & aprE3-5 & aprE-RT-F & 5'-TGGATCAGCTTGTTGTTTGCG-3' & $1 \mathrm{~kb}$ \\
\hline & & aprE-RT-R & 5'-GGGTGCTTAGAAAGGATTAGC-3' & \\
\hline & 16S rRNA & $27 \mathrm{~F}$ & 5'-AGAGTTTGATCCTGGCTCAG-3' & $1.5 \mathrm{~kb}$ \\
\hline & & $1492 \mathrm{R}$ & 5'-GGTTACCTTGTTACGACTT-3' & \\
\hline \multirow[t]{4}{*}{ qRT-PCR } & aprE3-5 & aprE-qRT-F & 5'-AACAGCAGCAACCAAAGAGC-3' & $178 \mathrm{bp}$ \\
\hline & & aprE-qRT-R & 5'-TCGGGTGCTTAGAAAGGAT-3' & \\
\hline & 16S rRNA & 16S-qRT-F & 5'-GAGTGACAGCTGGTGCATGGT-3' & $160 \mathrm{bp}$ \\
\hline & & 16S-qRT-R & 5'-TTGTCACCGGCAGTCACCTTA-3' & \\
\hline
\end{tabular}


Table 3. Primers used for construction of an aprE with tandem P10 promoter.

\begin{tabular}{|c|c|c|}
\hline Primers & Sequences & References \\
\hline aprE3-5-np-F & 5'CTGGATCCTCTTAAAAGGAGAGGGTAAAGAATGAGAAGCA-3" & This study \\
\hline aprE3-5-R & 5'- GCGAATTCGAGAACAGAGAAGCCGCT -3' & 13 \\
\hline MagaP10-F & $\begin{array}{l}\text { 5'AAGCTTCTAGAGATCTGCAGGTCGACGGGTTGACAAAAATATTATTCCATCT } \\
\text { ATTAAACTAAATTCACAGAATAGTCTTT -3' }\end{array}$ & This study \\
\hline MagaP10-R & $\begin{array}{l}\text { 5'-TTTTAAGAGGATCCAGAGTAGACTTACTTAAAAGACTATTCTGTGAATTTAG } \\
\text { TTTAATAGATGGAATAATATTTTTGTC -3' }\end{array}$ & This study \\
\hline Maga2P10-F & $\begin{array}{l}\text { 5'-GGCGGAGCCTATGGAAAAACGCTTTGCCCTTGACAAAAATATTATTCCATCT } \\
\text { ATTAAACTAAGCTT -3' }\end{array}$ & This study \\
\hline Maga2P10-R & $\begin{array}{l}\text { 5’-CCCGTCGACCTGCAGATCTCTAGAAGCTTAGTTTAATAGATGGAATAATATT } \\
\text { TTTGTCAAGGGCAA-3' }\end{array}$ & This study \\
\hline
\end{tabular}

The restriction site was underlined: BamHI (forward primer) and EcoRI (reverse primer).The -35 and - 10 promoter regions were in bold and underlined.

Green mix (Bio-Rad, USA), $1 \mu$ l of each primer, $7 \mu$ l of distilled water, and $1 \mu$ l of 200 -fold diluted cDNA product. The reactions were carried out using an instrument (CFX96, Bio-Rad). The relative gene expression was calculated by quantification cycle $(\mathrm{Cq})$ value with the $2^{-\Delta \Delta \mathrm{CT}}$ method [22]. The $16 \mathrm{~S}$ rRNA gene was used as a control, and all reactions were repeated 3 times.

\section{Construction of an aprE3-5 with 2 Copies of P10 Promoter in Tandem}

The primer pairs in Table 3 were used to construct an aprE3-5 containing 2 copies of P10 promoter in tandem. An aprE3-5 without its promoter was amplified from plasmid pHY3-5 by PCR using aprE3-5-np-F and aprE3-5-R primers, and the start codon was replaced from 'GTG' to 'ATG'. The reaction mixture (50 $\mu$ l) consisted of $1 \mu$ of template DNA, $1 \mu \mathrm{l}$ of each primer $(10 \mu \mathrm{M}), 5 \mu \mathrm{l}$ of dNTPs $(0.25 \mathrm{mM})$, and $0.5 \mu \mathrm{l}$ of ExTaq DNA polymerase (Takara, Tokyo, Japan). Amplification conditions were as follows: $94^{\circ} \mathrm{C}$ for $5 \mathrm{~min}, 30$ cycles of $94^{\circ} \mathrm{C}$ for $30 \mathrm{~s}, 64^{\circ} \mathrm{C}$ for $30 \mathrm{~s}, 72^{\circ} \mathrm{C}$ for $40 \mathrm{~s}$, and a final extension at $72^{\circ} \mathrm{C}$ for $5 \mathrm{~min}$. The purified DNA and pHY300PLK were digested with BamHI and EcoRI and ligated by T4 DNA ligase. The ligation mixture was used to transform E. coli DH5a competent cells, and the recombinant plasmid, pHYnpE2, without a promoter was obtained.

Following the Megawhop protocol [23], the P10 promoter was cloned into the upstream of aprE3-5 in pHYnpE2 using MegaP10-F and MegaP10-R primers. The PCR product was digested with DpnI, and the resulting plasmid was introduced into E. coli DH5a to obtain the plasmid pHYP10E2. Then, another P10 promoter was cloned into the $\mathrm{pHYP} 10 \mathrm{E} 2$ using Mega2P10-F and Mega2P10-R primers. The PCR product was digested with DpnI, and the resulting plasmid was introduced into $E$. coli DH5a to obtain the plasmid pHY2P10E2. pHYP10E2 and pHY2P10E2 were introduced into B. subtilis WB600 competent cells, respectively. The fibrinolytic activity assay, SDS-PAGE, and fibrin zymography were done to check the effect of tandem P10 promoters on the expression of aprE3-5.

\section{Results and Discussion}

\section{Construction of aprE3-5 Genes with Its Promoter Replaced with Other Promoter}

To increase the expression level of aprE3-5 in a heterologous Bacillus host, the -35 and -10 promoter sequences of aprE3-5 ( $\left.\mathrm{P}_{\text {aprE3-5 }}\right)$ were replaced with other strong Bacillus promoters without changes in the intervening sequences (Table 1). $\mathrm{P}_{\text {cry3Aa }}$ is a promoter modified from cry promoter of $B$. thuringiensis where the promoter is responsible for the overproduction of crystal proteins (Cry) [24]. The original -35 and -10 sequences of cry promoter were replaced with the consensus sequences of $\sigma^{\mathrm{A}}$ - dependent promoter of $B$. subtilis, generating $\mathrm{P}_{\text {cry3Aa }}$ [14]. $P_{10}$ promoter was derived from quorum sensing related promoter $P_{\text {srfa }}$ where the -35 sequence (GTGATA) was changed into the conserved sequence (TTGACA) [15]. $\mathrm{P}_{\mathrm{SGl}}$ (same with $\mathrm{P}_{\mathrm{SG}-\mathrm{TTGACA}}$ in the ref. 16) was derived from $\mathrm{P}_{\mathrm{SG} 35.1}$ where the -35 sequence (TACTAA) was replaced with the consensus sequence (TTGACA) [16]. $\mathrm{P}_{\text {srfA, }}$ has the same - 35 (GTGATA) and -10 sequences (TAAACT) of promoter of srfA [17]. These promoters were chosen because they do not require any specific inducer, which is expensive for large-scale cultivation and inconvenient, too.

Chimeric aprE3-5 genes with the replaced -35 and - 10 sequences were amplified by PCR (data not shown), and ligated with pHY300PLK. B. subtilis WB600 TFs harboring recombinant plasmids were obtained. DNA sequencing confirmed that the replaced -35 and - 10 promoter sequences were connected to the 1,146 bp aprE3-5 structural gene as expected (data not shown).

\section{Growth and Fibrinolytic Activities of B. subtilis WB600 TFs}

B. subtilis WB600 TFs harboring different plasmid constructs (original aprE3-5 gene and 4 chimeric genes) were inoculated into $\mathrm{LB}$ broth and cultured with shaking at $37^{\circ} \mathrm{C}$ for $96 \mathrm{~h}$. All strains grew well and $\mathrm{OD}_{600}$ values reached 1.5-1.7 after $24 \mathrm{~h}$ incubation, and the growth curve of each strain was similar (Fig. 1A). Culture carrying $\mathrm{P}_{\text {aprE3-5 }}$ showed fibrinolytic activity (FA) of $369.96 \mathrm{U} / \mathrm{ml}$ at $96 \mathrm{~h}$ of incubation whereas those of culture carrying $\mathrm{P}_{\text {cry3A }}, \mathrm{P}_{\text {srfA }}, \mathrm{P}_{10}$, or $\mathrm{P}_{\mathrm{SG} 1}$ were $376.22,460.85,628.15$, or $490.23 \mathrm{U} / \mathrm{ml}$, respectively (Fig. 1B). Except the strain carrying $\mathrm{P}_{\text {cry3aa, }}$ other strains showed significantly higher activities than the strain carrying the original promoter. The strain carrying $\mathrm{P}_{10}$ promoter showed the highest activity $(628.15 \mathrm{U} / \mathrm{ml})$, and the activity was 1.7 fold higher than that of the original strain $(369.96 \mathrm{U} / \mathrm{ml})$ at $96 \mathrm{~h}$ time point. The strain carrying $\mathrm{P}_{\mathrm{SG} 1}$ showed 1.3 fold higher 
A

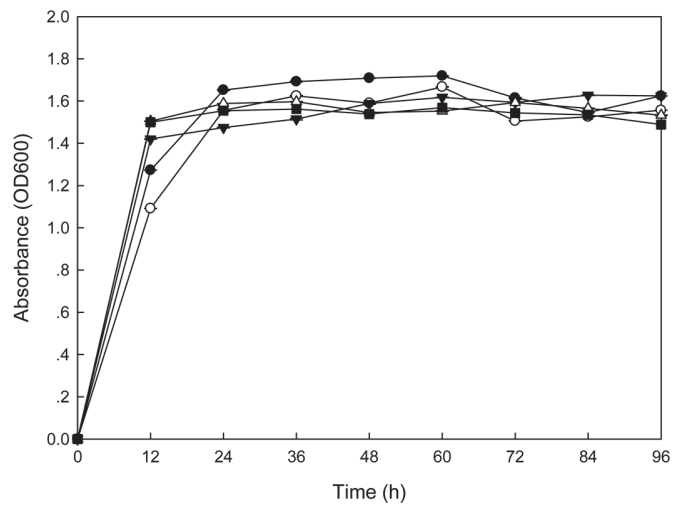

B

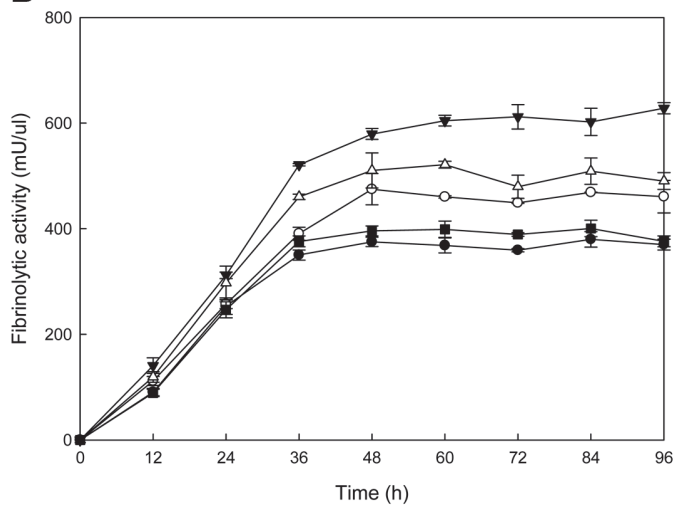

Fig. 1. Growth (A) and fibrinolytic activities (B) of B. subtilis WB600 TFs. B. subtilis TFs were cultivated for $96 \mathrm{~h}$ at $37^{\circ} \mathrm{C}$ in $\mathrm{LB}$ broth and the growth $\left(\mathrm{OD}_{600}\right)$ and fibrinolytic activities were measured at $12 \mathrm{~h}$ intervals. - - B. subtilis WB600 [pHY3-5]; - ○ -, B. subtilis WB600 [pHYsrfA]; - $\nabla$-, B. subtilis WB600 [pHYP10]; - $\triangle$-, B. subtilis WB600 [pHYPSG]; B. subtilis WB600 [pHYPcry3A].

activity. All strains showed similar pattern in fibrinolytic activity changes during the $96 \mathrm{~h}$ of incubation. The activities increased rapidly during the first $36 \mathrm{~h}$, and then increased gradually. The highest activities observed between 48 and $60 \mathrm{~h}$. However, the activity increased continuously until $96 \mathrm{~h}$ in the strain carrying pHYP10 (pHY300PLK with P10 promoter).

\section{SDS-PAGE and Fibrin Zymography}

Supernatant samples prepared at $48 \mathrm{~h}$ and $96 \mathrm{~h}$ were analyzed by SDS-PAGE and fibrin zymography using $10 \%$ acrylamide gels (Fig. 2). Four bands of 24, 28, 38 and $60 \mathrm{kDa}$ in size were observed on a coomassie blue stained gel (Fig. $2 \mathrm{~A}$ ) and one band $(28 \mathrm{kDa})$ was detected on a fibrin gel (Fig. 2B). The $28 \mathrm{kDa}$ protein was the mature form of AprE3-5. Culture carrying $\mathrm{P}_{10}$ promoter showed the strongest band intensity for $28 \mathrm{kDa}$ protein (Fig. $2 \mathrm{~A}$, lanes 7 , 8). The results indicated that AprE3-5 was overproduced from $\mathrm{P}_{10}$ promoter compared to other promoters. Similarly, the top regions of lanes 7 and 8 showed larger transparent areas than others. The big transparent region was suspected to be caused by binding of fibrinolytic enzymes to fibrin in the gel [25], and the size reflects the amount of the fibrinolytic enzymes in the sample. These results were consistent with the fibrinolytic activities of cultures (Fig. 1B).

\section{Reverse Transcription-qPCR Analysis}

RT-PCR was performed with RNA samples to confirm the aprE3-5 mRNA content in different samples. The expected amplified size of aprE3-5 was $1 \mathrm{~kb}$. The amplified size of 16S rRNA gene was $1.5 \mathrm{~kb}$. Agarose gel electrophoresis results confirmed 2 cDNA fragments with the matching sizes (Fig. 3A). The cDNA fragments in lane 1 and 2 were amplified aprE3-5, around $1 \mathrm{~kb}$, and the cDNA fragments in lane 3 and 4 were amplified 16S rRNA gene, around $1.5 \mathrm{~kb}$. The results showed that the concentration of aprE3-5 mRNA from the $\mathrm{P}_{10}$ carrying strain (lane 2) was significantly higher than that from the original strain (lane 1). The 16S rRNA gene concentrations were the same. The results showed qualitatively that the $\mathrm{P}_{10}$ promoter increased the frequency of transcription of aprE3-5.

A

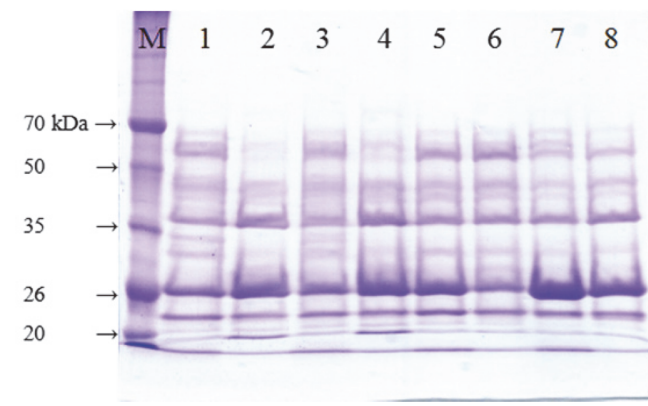

B

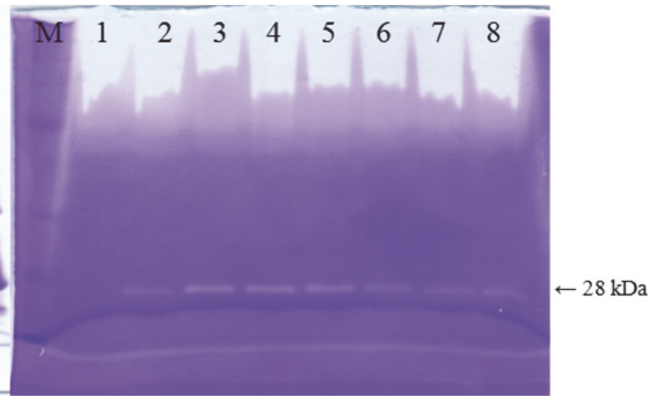

Fig. 2. Coomassie blue stained gel (A) and fibrin zymogram (B) of culture supernatant from $B$. subtilis WB600 TFs. M, Dokdo-marker (EBM-1034); lane 1, B. subtilis WB600 [pHY3-5] at 48 h; 2, at 96 h; 3, B. subtilis WB600 [pHYPsrfA] at $48 \mathrm{~h} ; 4$, at $96 \mathrm{~h} ; 5$, B. subtilis WB600 [pHYPSG] at $48 \mathrm{~h} ; 6$, at $96 \mathrm{~h} ; 7$, B. subtilis WB600 [pHYP10] at $48 \mathrm{~h} ; 8$, at $96 \mathrm{~h}$. 

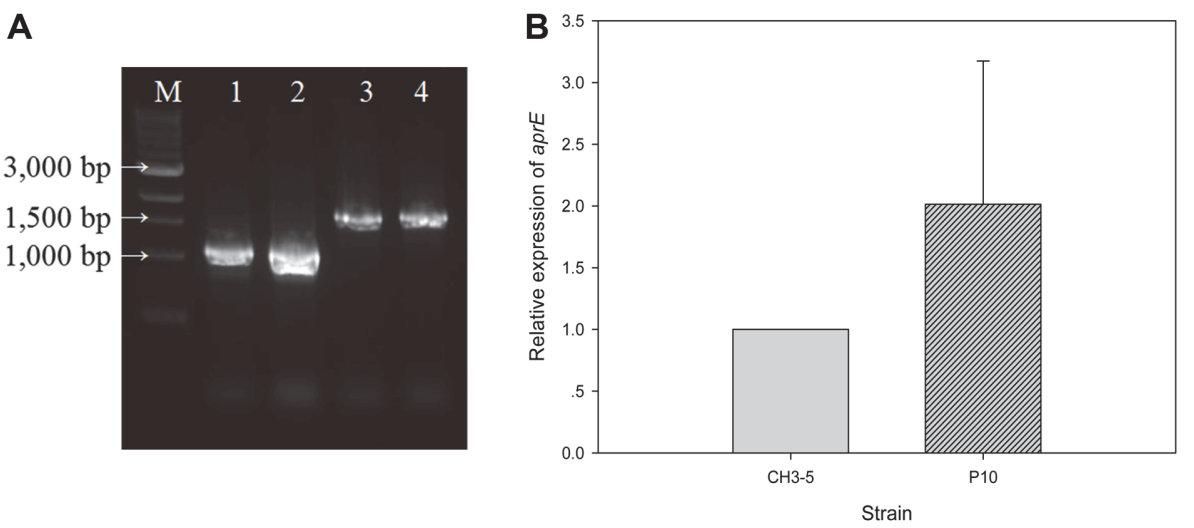

Fig. 3. Reverse Transcription (RT)-PCR (A) and the relative expression levels of aprE3-5 by its own promoter and replaced P10 promoter (B). M, iVDye 1kb DNA Ladder; 1-2, aprE3-5, RT-PCR product of B. subtilis WB600 [pHY35] (lane 1), and B. subtilis WB600 [pHYP10] (lane 2); 3-4, 16S rRNA gene, RT-PCR product of B. subtilis WB600 [pHY3-5] (lane 3), and B. subtilis WB600 [pHYP10] (lane 4).

Quantitative real-time PCR analysis was performed using the reverse transcription product as template to quantitatively analyze the effect by $\mathrm{P}_{10}$ promoter. Using $16 \mathrm{~S}$ rRNA gene as a control, the relative expression level of aprE3-5 was calculated using the $2^{-\triangle \triangle C T}$ method. The expression level of original strain was set to 1 . The expression of aprE3-5 gene by $\mathrm{P}_{10}$ promoter was significantly increased. At $48 \mathrm{~h}$ of incubation, the expression level was 2.01fold higher than that by the original promoter (Fig. 3B). The fibrinolytic activity of strain carrying $\mathrm{P}_{\text {aprE3-5}}$ or $\mathrm{P}_{10}$ was $375.15 \mathrm{U} / \mathrm{ml}$ and $579.33 \mathrm{U} / \mathrm{ml}$, respectively at $48 \mathrm{~h}$ of incubation. The strain carrying $\mathrm{P}_{10}$ promoter showed 1.54 fold higher fibrinolytic activity than that from the strain carrying the original promoter. The difference in gene expression matched with the fibrinolytic activities of cultures.

The -35 sequence of $\mathrm{P}_{10}$ was TTGACA, identical with the consensus - 35 sequence whereas that of the original aprE3-5 promoter is TCTACT. The -10 sequence of original aprE3-5 promoter and $\mathrm{P}_{10}$ are TACAAT and TAAACT, respectively. The -10 consensus sequence is TATAAT. Therefore the -10 sequence of original aprE3-5 promoter is more conserved than that of $\mathrm{P}_{10}$, and the results indicated that -35 sequence might contribute more to the overall promoter strength. Overproduction of valuable metabolites such as fibrinolytic enzymes can be achieved by many different methods, and the replacement of original promoter with stronger promoter is one option, which can be applied quickly and easily.

\section{Construction of aprE3-5 with 2 Copies of P10 Promoter in Tandem}

Bacillus strains harboring pHYP10, pHYP10E2, pHY2P10E2, or pHY300PLK (negative control), were obtained (Fig. 4), and cultivated in LB broth. Growth and fibrinolytic activities were measured (Fig. 5). All strains grew well, and showed the same absorbance values $(600 \mathrm{~nm})$ at $96 \mathrm{~h}$ (Fig. 5A). B. subtilis WB600 carrying pHY2P10E2 showed the highest fibrinolytic activity $(624.6 \mathrm{mU} / \mu \mathrm{l})$ at $96 \mathrm{~h}$ (Fig. 5B). Cells carrying pHYP10E2 was the next, $495.0 \mathrm{mU} / \mu \mathrm{l}$. Cells carrying pHY10 showed the activity of $423.3 \mathrm{mU} / \mathrm{ml}$. The activity of the strain carrying pHYP10E2 (ATG start codon) was 117\% higher than that of the strain carrying pHYP10, indicating that ATG was better than GTG for gene expression. The activity of the strain carrying pHY2P10E2 was $148 \%$ higher than that of the strain carrying pHYP10. The results indicated that 2 copies of P10 promoter in tandem further improved the gene expression level of aprE3-5 in B. subtilis.

SDS-PAGE and fibrin zymography were done for culture supernatants obtained at $12 \mathrm{~h}$ and $96 \mathrm{~h}$. Four bands of $24,28,38$, and $60 \mathrm{kDa}$ were observed on the gel stained with coomassie brilliant blue (Fig. 6A). The $28 \mathrm{kDa}$ band was the most obvious, indicating that a large amount of AprE3-5 was produced. On the fibrin zymogram (Fig. 6B), the size of transparent zone at the top of a fibrin gel reflected the fibrinolytic activity of a sample. The sizes of the transparent areas at the top of lanes 1,3, and 5 were similar with each other, indicating that the activity difference between samples at $12 \mathrm{~h}$ was not significant. But the bands with a size of $28 \mathrm{kDa}$ were observed at $96 \mathrm{~h}$ samples

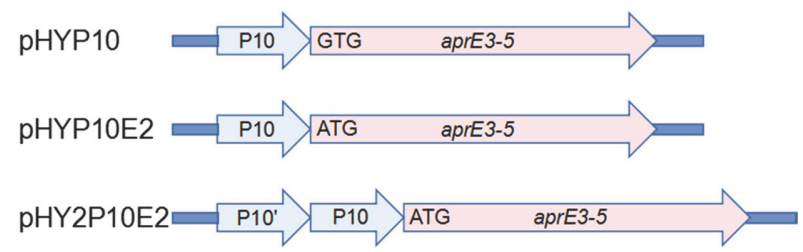

Fig. 4. The schematic diagram of the expression cassettes. pHYP10, pHY300PLK containing the aprE3-5 where the original promoter was replaced with -35 and -10 sequences from P10 promoter. pHYP10E2, pHYP10 where the start codon was changed from GTG to ATG. pHY2P10E2, pHYP10E2 where an additional P10 promoter was placed in tandem. 
A

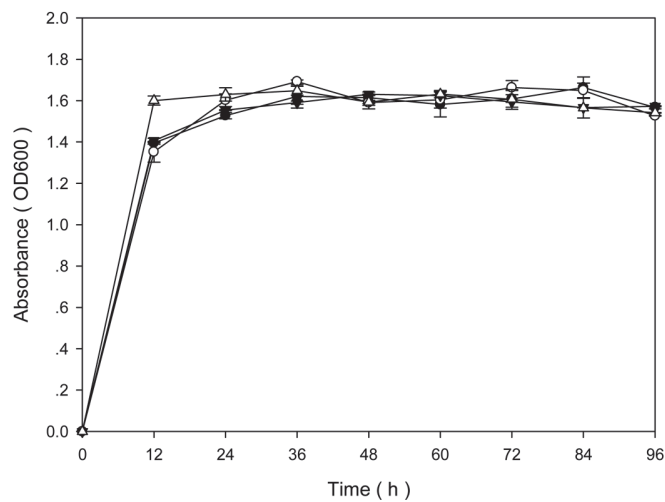

B

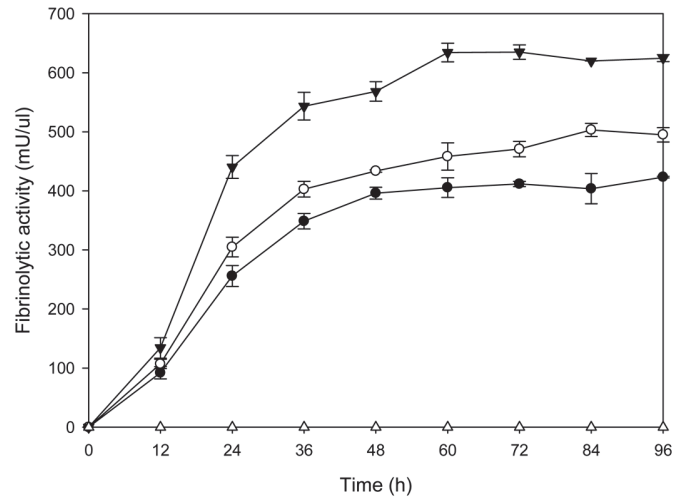

Fig. 5. Growth (A) and fibrinolytic activities (B) of B. subtilis WB600 TFs. B. subtilis TFs were cultivated for $96 \mathrm{~h}$ at $37^{\circ} \mathrm{C}$ in $\mathrm{LB}$ broth and the growth $\left(\mathrm{OD}_{600}\right)$ and fibrinolytic activities were measured at $12 \mathrm{~h}$ intervals. - -, B. subtilis WB600 [pHYP10]; - О-, B. subtilis WB600 [pHYP10E2]; - - , B. subtilis WB600 [pHY2P10E2]; - $\triangle-$, B. subtilis WB600 [pHY300PLK].

A

B

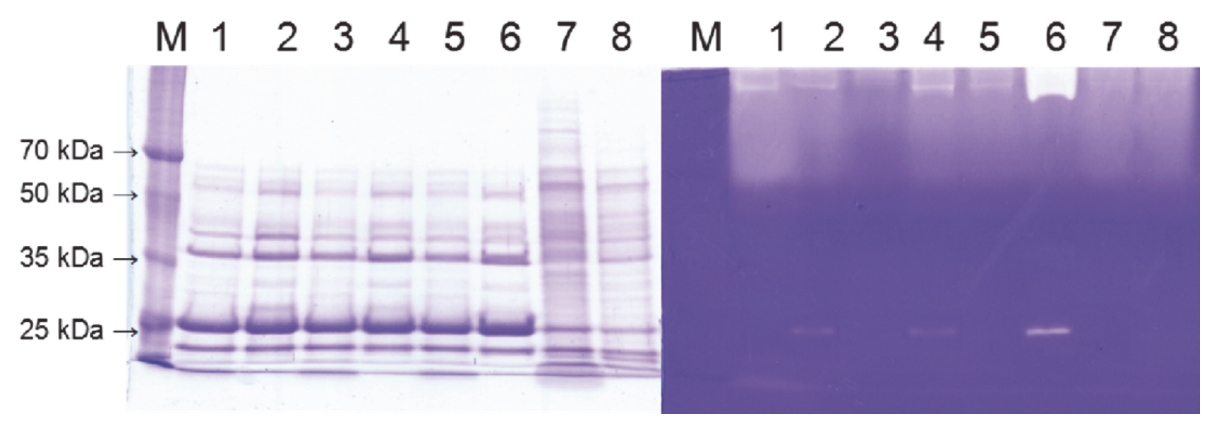

Fig. 6. Coomassie blue stained gel (A) and fibrin zymogram (B) of culture supernatant from $B$. subtilis WB600 TFs. M, Dokdo-marker (EBM-1034); lane 1, B. subtilis WB600 [pHYP10] at 12 h; 2, at 96 h; 3, B. subtilis WB600 [pHYP10E2] at $12 \mathrm{~h} ; 4$, at $96 \mathrm{~h} ; 5$, B. subtilis WB600 [pHY2P10E2] at $12 \mathrm{~h} ; 6$, at $96 \mathrm{~h} ; 7$, B. subtilis WB600 [pHY300PLK] at $12 \mathrm{~h}$; 8 , at $96 \mathrm{~h}$.

(lane 2, 4, and 6), indicating that AprE3-5 production occurred at late growth phase or early stationary phase. Especially the clear zone of lane 6 was the largest, indicating that pHY2P10E2 conferred the highest fibrinolytic activity to B. subtilis host. More directly, the band intensity of the $28 \mathrm{kDa}$ protein was the strongest in lane $6,96 \mathrm{~h}$ sample from $B$. subtilis carrying pHY2P10E2. The results were consistent with the fibrinolytic activity measurements of the cultures (Fig. 5B).

We successfully showed that the tandem P10 promoter increased the production of AprE3-5. In order to increase the production of AprE3-5 even further, it is necessary to conduct more researches on other elements which also might be important for overproduction of AprE3-5. These include the optimization of Shine-Dalgarno sequence, adjustments of the length of intervening sequence between - 35 and - 10 promoter sequences, and the use of transcription terminator [26]. Further studies are necessary on these topics in addition to optimization in media composition and cultural conditions.

\section{Acknowledgments}

This work was supported by the Basic Science Research Program through the National Research Foundation of Korea (NRF) funded by the Ministry of Education (2017R1D1A1B03030037) and also by a NRF grant funded by the Korea government (MSIT) (NRF-2020R1A2C100826711). Yao Z, Meng Y, Lee SJ, Jeon HS, and Yoo JY were supported by BK21 program, MOE, Republic of Korea. Le HG was supported by full time graduate student scholarship from Gyeongsang National University.

\section{Conflict of Interest}

The authors have no financial conflicts of interest to declare. 


\section{References}

1. Chen H, McGowan EM, Ren N, Lal S, Nassif N, Shad-Kaneez F, et al. 2018. Nattokinase: a promising alternative in prevention and treatment of cardiovascular diseases. Biomark. Insights 13: 117271918785130.

2. Omura K, Hitosugi M, Zhu X, Ikeda M, Maeda H, Tokudome S. 2005. A newly derived protein from Bacillus subtilis natto with both antithrombotic and fibrinolytic effects. J. Pharmacol. Sci. 99: 247-251.

3. Cai D, Zhu C, Chen S. 2017. Microbial production of nattokinase: current progress, challenge and prospect. World J. Microbiol. Biotechnol. 33: 84 .

4. Agrebi R, Haddar A, Hajji M, Frikha F, Manni L, Jellouli K, et al. 2009. Fibrinolytic enzymes from a newly isolated marine bacterium Bacillus subtilis A26: characterization and statistical media optimization. Can. J. Microbiol. 55: 1049-1061.

5. Man LL, Xiang DJ, Zhang CL. 2019. Strain screening from traditional fermented soybean foods and induction of nattokinase production in Bacillus subtilis MX-6. Probiotics Antimicrob. Proteins 11: 283-294.

6. Kwon EY, Kim KM, Kim MK, Lee IY, Kim BS. 2011. Production of nattokinase by high cell density fed-batch culture of Bacillus subtilis. Bioprocess Biosyst. Eng. 34: 789-793.

7. Unrean P, Nguyen NHA. 2013. Metabolic pathway analysis and kinetic studies for production of nattokinase in Bacillus subtilis. Bioprocess Biosyst. Eng. 36: 45-56.

8. Chen PT, Shaw JF, Chao YP, Ho THD, Yu SM. 2010. Construction of chromosomally located T7 expression system for production of heterologous secreted proteins in Bacillus subtilis. J. Agric. Food Chem. 58: 5392-5399.

9. Jeong SJ, Park JY, Lee JY, Lee KW, Cho KM, Kim GM, et al. 2015. Improvement of fibrinolytic activity of Bacillus subtilis 168 by integration of a fibrinolytic gene into the chromosome. J. Microbiol. Biotechnol. 25: 1863-1870.

10. Cai Y, Bao W, Jiang S, Weng M, Jia Y, Yin Y, et al. 2011. Directed evolution improves the fibrinolytic activity of nattokinase from Bacillus natto. FEMS Microobiol. Lett. 325: 155-161.

11. Kim J, Kim JH, Choi KH, Kim JH, Song YS, Cha J. 2011. Enhancement of the catalytic activity of a $27 \mathrm{kDa}$ subtilisin-like enzyme from Bacillus amyloliquefaciens CH51 by in vitro mutagenesis. J. Agric. Food Chem. 59: 8675-8682.

12. Liu Z, Zheng W, Ge C, Cui W, Zhou L, Zhou Z. 2019. High-level extracellular production of recombinant nattokinase in Bacillus subtilis WB800 by multiple tandem promoters. BMC Microbiol. 19: 89.

13. Jeong SJ, Kwon GH, Chun JY, Kim JS, Park CS, Kwon DY, et al. 2007. Cloning of fibrinolytic enzyme gene from Bacillus subtilis isolated from Cheonggukjang and its expression in protease-deficient Bacillus subtilis strains. J. Microbiol. Biotechnol. 17: 1018-1023.

14. Haldenwang WG. 1995. The sigma factors of Bacillus subtilis. Microbiol. Rev. 59: 1-30.

15. Cheng J, Guan C, Cui W, Zhou L, Liu Z, Li W, et al. 2016. Enhancement of a high efficient autoinducible expression system in Bacillus subtilis by promoter engineering. Protein Expr. Purif. 127: 81-87.

16. Jan J, Valle F, Bolivar F, Merino E. 2001. Construction of protein overproducer strains in Bacillus subtilis by an integrative approach. Appl. Microbiol. Biotechnol. 55: 69-75.

17. Han LC, Suo FY, Jiang C, Gu J, Li NN, Zhang NX, et al. 2017. Fabrication and characterization of a robust and strong bacterial promoter from a semi-rationally engineered promoter library in Bacillus subtilis. Process Biochem. 61: 56-62.

18. Wu XC, Lee W, Tran L, Wong SL. 1991. Engineering a Bacillus subtilis expression-secretion system with a strain deficient in six extracellular proteases. J. Bacteriol. 173: 4952-4958.

19. Sambrook J, Russell DW. 2001. Molecular cloning: a laboratory manual, 3rd Ed. Cold Spring Harbor Laboratory Press, Cold Spring Harbor, NY, USA.

20. Yao Z, Liu X, Shim JM, Lee KW, Kim HJ, Kim JH. 2017. Properties of a fibrinolytic enzyme secreted by Bacillus amyloliquefaciens RSB34, isolated from doenjang. J. Microbiol. Biotechnol. 27: 9-18.

21. Meng L, Feldman L. 2010. A rapid TRIzol-based two-step method for DNA-free RNA extraction from Arabidopsis siliques and dry seeds. Biotechnol. J. 5: 183-186.

22. Livak KJ, Schmittgen TD. 2001. Analysis of relative gene expression data using real-time quantitative PCR and the $2^{-\Delta \Delta C T}$ method. Methods 25: 402-408.

23. Miyazaki K. 2011. MEGAWHOP cloning: a method of creating random mutagenesis libraries via megaprimer PCR of whole plasmids. Methods Enzymol. 498: 399-406.

24. Lee SJ, Pan JG, Park SH, Choi SK. 2010. Development of a stationary phase-specific autoinducible expression system in Bacillus subtilis. J. Biotechnol. 149: 16-20.

25. Choi NS, Yoo KH, Yoon KS, Chang KT, Maeng PJ, Kim SH. 2005. Identification of recombinant subtilisins. J. Microbiol. Biotechnol. 15: 35-39.

26. Chen J, Gai Y, Fu G, Zhou W, Zhang D, Wen J. 2015. Enhanced extracellular production of a-amylase in Bacillus subtilis by optimization of regulatory elements and over-expression of PrsA lipoprotein. Biotechnol. Lett. 37: 899-906. 